\title{
Prediction of junior faculty success in biomedical research: Comparison of metrics and effects of mentoring programs
}

Christopher von Bartheld, Ramona Houmanfar, Amber Candido

Measuring and predicting the success of junior faculty is of considerable interest to faculty, academic institutions, funding agencies and faculty development and mentoring programs. Various metrics have been proposed to evaluate and predict research success and impact, such as the $\mathrm{h}$-index, and modifications of this index, but they have not been evaluated and validated side-by-side in a rigorous empirical study. Our study provides a retrospective analysis of how well bibliographic metrics and formulas (numbers of total, first- and coauthored papers in the PubMed database, numbers of papers in high-impact journals) would have predicted the success of biomedical investigators $(n=40)$ affiliated with the University of Nevada, Reno, prior to, and after completion of significant mentoring and research support (through funded Centers of Biomedical Research Excellence, COBREs), or lack thereof (unfunded COBREs), in 2000-2014. The h-index and similar indices had little prognostic value. Publishing as mid- or even first author in only one high-impact journal was poorly correlated with future success. Remarkably, junior investigators with $>6$ firstauthor papers within 10 years were significantly $(p<0.0001)$ more likely $(93 \%)$ to succeed than those with $\leq 6$ first-author papers $(4 \%)$, regardless of the journal's impact factor. The benefit of COBRE-support increased the success rate of junior faculty approximately 3-fold, from $15 \%$ to $47 \%$. Our work defines a previously neglected set of metrics that predicted the success of junior faculty with high fidelity - thus defining the pool of faculty that will benefit the most from faculty development programs such as COBREs. 
5 Prediction of junior faculty success in biomedical research: Comparison of metrics and

effects of mentoring programs

8 Christopher S. von Bartheld ${ }^{1 *}$, Ramona Houmanfar ${ }^{2}$, Amber Candido ${ }^{2}$

${ }^{1}$ Department of Physiology and Cell Biology, University of Nevada School of Medicine, Reno, $11 \quad$ NV 89557, USA

2 Department of Psychology, University of Nevada, Reno, NV 89557, USA

13

14

15 * Correspondence: Christopher von Bartheld, MD; Department of Physiology and Cell Biology,

16 Mailstop 352, University of Nevada School of Medicine, Reno, NV 89557 (USA); E-MAIL:

17 cvonbartheld@medicine.nevada.edu; Phone: 1-775-784-6022. 
19 Abstract Measuring and predicting the success of junior faculty is of considerable interest to

20 faculty, academic institutions, funding agencies and faculty development and mentoring

21 programs. Various metrics have been proposed to evaluate and predict research success and

22 impact, such as the h-index, and modifications of this index, but they have not been evaluated

23 and validated side-by-side in a rigorous empirical study. Our study provides a retrospective

24 analysis of how well bibliographic metrics and formulas (numbers of total, first- and co-authored

25 papers in the PubMed database, numbers of papers in high-impact journals) would have

26 predicted the success of biomedical investigators $(n=40)$ affiliated with the University of

27 Nevada, Reno, prior to, and after completion of significant mentoring and research support

28 (through funded Centers of Biomedical Research Excellence, COBREs), or lack thereof

29 (unfunded COBREs), in 2000-2014. The h-index and similar indices had little prognostic value.

30 Publishing as mid- or even first author in only one high-impact journal was poorly correlated

31 with future success. Remarkably, junior investigators with $>6$ first-author papers within 10 years

32 were significantly $(\mathrm{p}<0.0001)$ more likely $(93 \%)$ to succeed than those with $\leq 6$ first-author

33 papers (4\%), regardless of the journal's impact factor. The benefit of COBRE-support increased

34 the success rate of junior faculty approximately 3 -fold, from $15 \%$ to $47 \%$. Our work defines a

35 previously neglected set of metrics that predicted the success of junior faculty with high fidelity

36 - thus defining the pool of faculty that will benefit the most from faculty development programs

37 such as COBREs. 
Introduction

41 Faculty development has become the topic of considerable interest, with universities increasingly implementing formal mentoring programs to ensure that new faculty find suitable mentors and receive other help with career development (Thorndyke et al., 2006; Bland et al., 2009; Steinert et al., 2009; Bruce et al., 2011). In addition, federal agencies (e.g., National Institutes of Health, $\mathrm{NIH}$ ) are funding faculty development programs to reduce disparities in the geographic localization of biomedical research (Process Evaluation of the COBRE Program, 2008), to enhance diversity of the workforce (Page, Castillo-Page \& Wright, 2011), and to promote clinical and translational research (Meagher et al., 2011; Knapke et al., 2013; Knapke et al., 2015).

Sponsors such as the NIH have been collecting metrics on these programs (Process Evaluation of the COBRE Program, 2008; Committee to evaluate the EPSCoR, 2013), showing success by various parameters. However, little attention has been directed either at the NIH or in evaluations of institution-based mentoring programs (Bruce et al., 2011; Wadhwa, Das \& Ratnapalan, 2014) as to which metrics may predict success of the junior faculty member, and which junior faculty members will most likely benefit from these programs and succeed. Faculty can be divided in three groups: those who don't need additional support to succeed; those who will never obtain independent research funding, regardless of the effort and money invested in their mentoring; and

57 the ones that fall between these two extremes. The latter are the ones who benefit the most from a mentoring program if it brings them across the threshold of where they can obtain independent status and maintain a productive, externally funded lab. But how does one identify these groups 60 in advance - how does one predict future success? 
62 Metrics to predict success and impact. Multiple types of metrics have been claimed or

63 proposed to measure academic research success and impact, including publication record: many

64 publications, early publications, papers published in journals with high impact factors (IFs), first

65 author papers, any co-authored papers, papers with high citation rates - as first author or as any

66 (co-)author (Khanna and Mouw, 1993; Symonds, 2004; Hirsch, 2007; Acuna, Allesina \&

67 Kording, 2012; Laurance et al., 2013; Carpenter, Cone \& Sarli, 2014; van Dijk, Manor \& Carey,

68 2014). One metric that has been gaining considerable popularity, due to its simplicity, is the h-

69 index (Hirsch, 2005). This index is used to measure the research impact of scientists, and it is

70 provided in major databases such as Web of Science and Scopus (Bakkalbasi et al., 2006; Falagas

71 et al., 2008). However, a major criticism of the h-index has been that it does not distinguish

72 whether an author is the first or last author (both of whom together should get most of the credit),

73 or just one of potentially hundreds of co-authors with minimal contributions (Schreiber, 2008;

74 Bornmann et al., 2011; Romanovsky, 2012; Biswal, 2013; Carpenter, Cone \& Sarli, 2014). This

75 has led to multiple proposals of revised indices (Bornmann et al., 2011; Biswal, 2013; Carpenter,

76 Cone \& Sarli, 2014).

77 Since major obstacles to a meaningful program evaluation are "selection bias" and the

78 lack of a suitable control group for comparison (Sambunjak, Straus \& Marusic, 2006; Bruce et

79 al., 2011; Steinert, 2012; Committee to evaluate the EPSCoR, 2013), we took advantage of the

80 fact that our institution has competed in the last 15 years in multiple rounds of applications for

81 Centers of Biomedical Research Excellence (COBREs), with four completed successful COBREs

82 and four unsuccessful applications (with different teams of junior faculty). This provided a

83 sufficient " $\mathrm{n}$ " of faculty ( $\mathrm{n}=40$ ) to assess in a retrospective study the utility of metrics that have 
84 been proposed to predict faculty success and to quantify the impact of a substantial federally

85 funded mentoring program (COBRE).

87 Materials \& Methods

88

89 Faculty Inclusion Criteria. This project was reviewed by the University of Nevada, Reno Social

90 Behavior and Education IRB, and it was determined that this work does not constitute human

91 subject research and does not require human research protection oversight by the IRB. We

92 compiled metrics and examined and compared the bibliographic output and grant support of all

93 those junior faculty at the University of Nevada, Reno, that were proposed between 2000 and

942014 to become project leaders in a COBRE mentoring program and were actually supported for

95 at least two years in such a program (= "mentored group"), or were proposed for such a position

96 but the COBRE was not funded (control group). We will refer to the COBRE-supported group as

97 the "mentored group," but caution the reader to keep in mind that mentoring is only part of the

98 benefits of COBRE support. COBREs provide up to five years of research funding for junior

99 faculty (phase I), and each COBRE can be competitively renewed after five years for a second

100 five-year period (phase II). Among our institution's $\sim 90$ biomedical faculty, approximately 30-35

101 are eligible to become COBRE project leaders. Between 2000 and 2014, four COBREs were

102 funded, two completed phases I and II, two are currently in phase I, and four proposed COBREs

103 were not funded, providing a total of $n=40$ faculty, with $n=20$ for the mentored group, and $n=20$

104 for the control group. When an unfunded COBRE was resubmitted in the following year with the

105 same team of junior faculty, only the first year of submission was considered, to not duplicate

106 results. Occasionally, junior faculty moved from a phase I COBRE to a phase II COBRE ( $n=5$; 
107 only two faculty completed a total of 10 years of COBRE funding), or moved from an unfunded

108 COBRE to a funded COBRE ( $\mathrm{n}=3$ ), or were included in different years on two different unfunded

109 COBREs $(\mathrm{n}=2)$, but those were a relatively small proportion of the total number of junior faculty

110 ( $\mathrm{n}=40$ ). Junior faculty were defined according to COBRE rules as faculty who had not yet served

111 as principal investigator on an NIH R01 grant or a comparably large grant project.

113 Metrics. Entire PubMed bibliographies were established for each of the faculty. Moreover, all

114 citations as per Web of Science ${ }^{\mathrm{TM}}$ Core Collection, Basic Search, were compiled for the year up

115 to and including the proposed start date of the COBRE to determine the h-index (Hirsch, 2005) at

116 that time, i.e., the start of mentoring/research support (or proposed, if not funded). A scientist has

117 index $\mathrm{h}$ if $\mathrm{h}$ of his/her $\mathrm{N}_{\mathrm{p}}$ papers have at least $\mathrm{h}$ citations each, and the other $\left(\mathrm{N}_{\mathrm{p}}-\mathrm{h}\right)$ papers have no

118 more than $\mathrm{h}$ citations each (Hirsch, 2005). The same data were used to calculate another index,

119 the Ab-index that takes into account multiple authorship (Biswal, 2013). In addition, the number

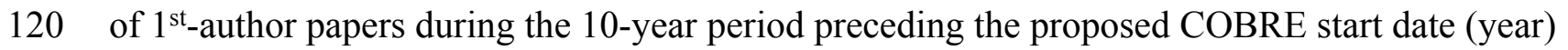

121 was determined for each faculty. In one case, a faculty member had already made the transition

122 from $1^{\text {st }}$-author publishing to last-author publishing; in this case, the number of last-authored

123 papers was counted instead of the number of $1^{\text {st }}$-authored papers for the same 10 -year period. We

124 also counted the number of first-authored and the number of co-authored (middle author) papers

125 in PubMed with a high (>9) journal impact factor. Finally, the number of last-author papers was

126 determined for all faculty during and upon graduation from the COBRE program (or a

127 comparable time frame when the COBRE was not funded). All investigators considered here

128 followed the convention where senior authorship (corresponding authorship) is expressed by last-

129 author position among authors. A successful faculty was defined as having external (not only 
130 COBRE-funding) of any amount and duration (in all of our cases at least two years of funding),

131 and in addition publishing on average at least one last-author (=senior author) paper in PubMed

132 per year during or upon graduation from the COBRE (or a comparable time frame when the

133 COBRE was not funded). This definition combines two key features of how academic centers

134 evaluate faculty's research success: extramural funding and peer-reviewed publications (Kairouz

135 et al., 2014). Senior-author publications during COBRE support were not counted towards this

136 number if other external grant support was lacking, in order to evaluate true independence from

137 COBRE support. Note that this definition does not require that the successful faculty remain

138 located in the USA (occasionally, project leaders were offered and they accepted academic

139 positions outside the USA). Simply staying on COBRE funds for extended periods of time

140 without other external grant support was not considered an independent, externally funded and

141 successful investigator in biomedical research. NIH grant awards were verified in the public

142 database, NIH Reporter (http://projectreporter.nih.gov/reporter.cfm), and information about other

143 external grant funding was obtained by grant citations. Information about the ranking of the

144 University of Nevada, Reno was obtained from www.arwu.org, and statistics software used was

145 SPSS version 23 (IBM, Armonk, NY).

148 Results

Characterization of groups. We first compared the metrics that were compiled for the

151 two groups, the control vs. mentored (= COBRE-supported) groups, to verify that they were

152 essentially equivalent. As shown in Table 1, the h-indices for the two groups of faculty at the start 
153 of mentoring (or lack thereof) were very similar - 10.65 vs. 12.00 (statistically not different) and

154 the Ab-indices were 177.6 vs. 148.6 (again statistically not different). The mean number of total

155 papers in PubMed during the 10 years prior to proposed mentoring start, per faculty, was 14.9 vs.

156 17.5, again not a significant difference. The number of $1^{\text {st }}$-author papers in PubMed differed by

157 less than 2.5 (6.85 vs. 4.45), statistically insignificant (see Table 1). The number of first author

158 papers in high-impact journals, defined as journals with an impact factor (IF) $>9$, was a mean of

1590.9 for the control, and a mean of 0.8 per faculty in the mentored group. The number of co-

160 authored papers in high impact journals was 2.35 for the control, and 1.35 per faculty in the

161 mentored group (statistically insignificant). The gender of junior faculty was $50 \%$ female vs. $50 \%$

162 male for the control, and $25 \%$ female vs. $75 \%$ male for the mentored group. The delay between

163 first publication (in PubMed) and proposed COBRE start date was 14.0 years for the control, and

16410.9 years for the mentored group (statistically insignificant difference, Table 1). Thus, the two

165 groups were well-matched by h-index and Ab-index, with the investigators on funded COBREs

166 having published slightly more $1^{\text {st }}$-author papers, but having published less of these $1^{\text {st }}$-author

167 papers (and co-authored papers) in high impact factor journals than the investigators proposed for

168 unfunded COBREs.

169

170

TABLE 1 ABOUT HERE

171

172

Success rate of junior faculty. The success rate, defined as external funding and at least

173 one paper in the PubMed database per year (on average) as senior author, was $3 / 20=15 \%$ for

174 faculty in unfunded COBREs (the "baseline", $n=20)$ and 8/17=47.1\% ( $n=17)$ after COBRE-

175 support and mentoring (see Table 2, a significant difference with $\mathrm{p}=0.0404$ ). For the purposes of 
176 calculating the success rate, we did not include faculty of the current COBREs at the University

177 of Nevada, Reno, (since it is too early to evaluate them - for this reason there is an $n=17$ for the

178 comparison of success rates). Accordingly, the COBRE support and mentoring increased the

179 success of faculty by over 3 -fold (or by $213 \%$ ). Male faculty were more successful than female

180 faculty. Faculty with English as $2^{\text {nd }}$ language had more success (8/18=44.4\%) than native English

181 speakers $(6 / 22=27.3 \%)$. The fraction of ethnic minorities was too small for any meaningful

182 conclusions. Previous studies have indicated that mentoring programs increase the retention of

183 faculty (Wingard, Garman \& Reznik, 2004; Sambunjak, Straus \& Marusic, 2006; Bland et al.,

184 2009). Among the mentored faculty (1-15 years after onset) retention was $64.7 \%$ (11/17), up

185 from a baseline of $40.0 \%(8 / 20)$ (Table 2 , although this increase was not statistically significant,

$186 \mathrm{p}>0.1)$. The difference in delay between first publication and proposed COBRE start date (14.0

187 years for the mentored group; 10.9 years for the control group) cannot explain the difference in

188 success, because the successful faculty had a mean delay of 10.8 years, while the non-successful

189 faculty had a mean delay of 13.4 years, so the non-successful faculty actually had more years of

190 experience than the successful faculty. COBRE mentoring reduced the time required to obtain

191 external funding from 3.9 to 3.4 years, but the decrease was not statistically significant. For

192 successful faculty (per our definition of success), COBRE mentoring reduced the time between

193 proposed start of mentoring and external funding from a mean of 4.0 to 3.0 years (not statistically

194 significant).

195

196

TABLE 2 ABOUT HERE

197 
Utility of metrics for prediction of success. We first tested the h-index, since it is widely

199 believed to have predictive power (Hirsch, 2007; Acuna, Allesina \& Kording, 2012; van Dijk,

200 Manor \& Carey, 2014). The h-index at the start of proposed COBRE funding was $12.00 \pm 1.28$

201 (SEM) for successful faculty, and 10.65 \pm 1.27 for non-successful faculty (insignificant

202 difference); accordingly, the h-index did not distinguish between successful and unsuccessful

203 faculty. When we plotted the h-indices within sub-groups, there was no predictive value, except

204 for a trend for more success with mid-level h-indices (see Fig. 1). The Ab-index, which

205 proportions citations according to the author rank (Biswal, 2013), was 148.6 \pm 28.2 for the

206 mentored group, and 177.6 \pm 37.8 for the control group, with no statistically significant difference.

207 Accordingly, even when controlled for citations as co-author, the index did not distinguish

208 between successful and non-successful faculty. When the Ab-index was plotted according to sub-

209 groups, a bi-phasic curve emerged, with the lowest chance of success for the lowest and highest

210 Ab-indices (0-50 and above 500), and the best chance of success (nearly $60 \%$ ) in the range of

$21175-200$ (see Fig. 1).

212

213

FIGURE 1 ABOUT HERE

214

215

Examination of authorship metrics. The number of total papers published in PubMed

216 (including co-author, $1^{\text {st }}$-author, and last-author papers at the start of COBRE funding or the

217 proposed start date) showed a trend from generally lower success rates with low numbers of

218 papers (0-15), and higher success rates with larger numbers of papers (15-45, Fig. 2), but the

219 pattern did not reflect and discriminate between the successful and the non-successful faculty,

220 and therefore would be of limited use to identify groups. Faculty success has been linked to 
221 publishing in top journals (Symonds, 2004; Carpenter, Cone \& Sarli, 2014; van Dijk, Manor \&

222 Carey, 2014). We therefore examined the numbers of papers in high-impact factor (IF $>9$ )

223 journals. There was no difference between chances of faculty for success with none or one $1^{\text {st }}$

224 author high impact journal paper, but when the number of $1^{\text {st }}$-author papers in journals with high

225 impact factors increased to two or more, there was a strong correlation with success $\left(\mathrm{r}^{2}=0.703\right.$,

226 Fig. 2). The number of co-authored (middle author) papers in high impact journals did not

227 correlate with faculty's success - in fact, successful faculty published fewer high impact papers

228 as co-authors (1.50 per faculty) than non-successful faculty (2.04 per faculty, statistically

229 insignificant). Accordingly, publishing as a co-author in high impact journals does not increase

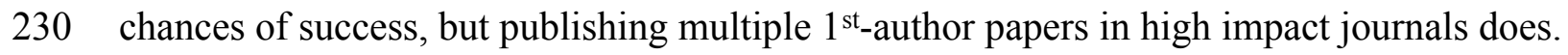

231

232

233

234

235

236

237

238

239

240

241 242 preceding 10 years is the most powerful predictor of biomedical research success, as per our 243 definition of faculty success.

FIGURE 2 ABOUT HERE

Next, we examined whether the number of $1^{\text {st }}$-author papers in any PubMed-listed journal (regardless of the journal's impact factor) would predict success. There was a near perfect $(38 / 40=95.0 \%$ correct $)$ prediction of success, showing a very small chance $(1 / 24=4.1 \%)$ of success for faculty with six or less $1^{\text {st }}$-author papers in the 10 years prior to the year of proposed COBRE funding, and a very high chance (13/14=92.9\%) of success for those with seven or more $1^{\text {st }}$-author papers (see Fig. 3). Accordingly, the number of $1^{\text {st }}$-author papers in PubMed distinguishes with high precision $(\mathrm{p}<0.0005)$ between successful and non-successful junior

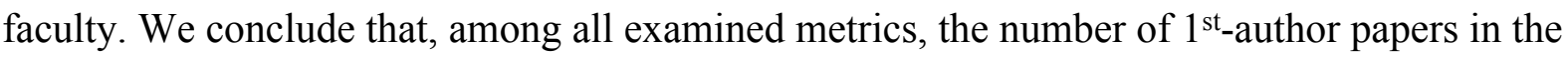


FIGURE 3 ABOUT HERE

\section{Discussion}

Our study is the first retrospective, empirical study that compares the long-term effectiveness of a faculty mentoring and research support program with a suitable control group. Utilizing an appropriate control group is required, but often lacking in the research design of program evaluations (Jacobi, 1991; Morzinski and Fisher, 1996; Steinert, 2000; Sambunjak, Straus \& Marusic, 2006; Steinert, 2012). Furthermore, we identify a simple, easy-to-use metric that predicts faculty success much more reliably than several previously proposed indices, such as the h-index and the Ab-index. Our work helps to define a pool of junior faculty that presents a prime target for faculty development resources, and, once externally validated, should make such programs more efficient and successful.

Measuring effectiveness of faculty development programs. Previous attempts to define mentoring success have been criticized for lack of adequate control groups and for relying on self-report and participant satisfaction - essentially testimonials and opinions (Sheets and

262 Schwenk, 1990; Jacobi, 1991; Morzinski and Fisher, 1996; Buddeberg-Fischer et al., 2006;

263 Sambunjak, Straus \& Marusic, 2006; Thorndyke, Gusic \& Milner, 2008; Bruce et al., 2011). One 264 major novel feature of our study is the comparison with a near optimal control group - junior 265 faculty who were deemed sufficiently competitive to be included in a COBRE grant proposal as 266 project leaders. This is about as close as ethically possible to a truly randomized trial. 
267 Accordingly, our two groups were not likely to be skewed by "selection bias" (Jacobi, 1991;

268 Bruce et al., 2011).

269 Our study validates the design and implementation of NIH-funded mentoring and research

270 support, especially the COBRE faculty development program, which we show increases faculty

271 success by more than 3 -fold. This amount of increase is somewhat larger than that (2.4-fold

272 increase) reported for another mentoring program, the NIH-funded program by the Advanced

273 Research Institute (ARI) in geriatric mental health at Cornell (Bruce et al., 2011). This two-year

274 program targets scholars nationwide that are midway through a mentored career development

275 award. The authors of the ARI program, however, did not compare their results with a local

276 control group within a similar academic environment. To our knowledge, an average increase in

277 junior faculty success of over 3 -fold is the first "hard" number obtained in a controlled study for a

278 faculty development program (COBRE) that invests $\$ 170$ million annually and over $\$ 2$ billion

279 since inception in 2000 (Committee to evaluate EPSCoR, 2013). Accordingly, our study lends

280 support to the effectiveness of this NIH-funded program.

281 Female junior faculty were less successful (as defined above) than male faculty at our

282 institution (see Table 2) - similar to previous studies (Laurance et al., 2013; van Dijk, Manor \&

283 Carey, 2014). Time constraints during a critical period of a scientist (grad student/post-doc

284 productivity) may compete with child-bearing and responsibilities of raising a family (Ceci and

285 Williams, 2011), but this is a complex issue and additional factors, including gender bias in the

286 academic community, have been well documented to be relevant factors (Fried et al., 1996;

287 Steinpreis, Anders \& Ritzke, 1999; Moss-Racusin et al., 2012). When female faculty published

288 beyond the critical 6 first-authored papers, they appeared to be on track for success, comparable 
289 to their male counterparts, suggesting that the obstacles are at earlier rather than later stages of 290 career development.

291

292 Prediction of junior faculty success. Attempts to predict faculty success or any trainee's success

293 have a long history (Creswell, 1986; Jacobi, 1991; Khanna and Mouw, 1993; Olds, 2001;

294 Symonds, 2004; Hirsch, 2007; Acuna, Allesina \& Kording, 2012; McNutt, 2014; van Dijk,

295 Manor \& Carey, 2014; Wadhwa, Das \& Ratnapalan, 2014). Recent work has proposed to utilize

296 various metrics to define who is most likely to succeed. These metrics have included aspects of

297 the publication record: number of publications, early publications, papers published in journals

298 with high impact factors (IFs), papers published in Science or Nature (Symonds, 2004), $1^{\text {st }}$-author

299 papers, any co-authored papers, papers with high citation rates - as first author or as any

300 (co)author (Acuna, Allesina \& Kording, 2012; Laurance et al., 2013; van Dijk, Manor \& Carey,

301 2014), but also aspects of training (reputation of the advisor, lab, or university for graduate work

302 or post-graduate work (Acuna, Allesina \& Kording, 2012; Laurance et al., 2013; van Dijk, Manor

303 \& Carey, 2014), as well as factors such as gender, with being male giving a significant advantage

304 (Laurance et al., 2013; van Dijk, Manor \& Carey, 2014).

305 Being a native English speaker is also thought to convey a small, but measurable boost,

306 albeit with great variation among individuals (Laurance et al., 2013). This seems to be a

307 discrepancy with our finding of second language English speakers being more successful than

308 native English speakers. We considered that two differences between studies may be relevant:

309 Laurance et al. studied academicians throughout the world (where many languages compete),

310 while our study was at one university in the USA (where second language English speakers

311 compete primarily with native English speakers). Furthermore, Laurance et al. measured total 
312 number of publications (regardless of first-author status), while we report the success of those

313 faculty with a large number of $1^{\text {st }}$ author publications. To determine whether the latter difference

314 plays a role, we compared the variable of native English vs. English as second language for all

315 publications in our database. Our analysis indicates that faculty with English as second language

316 published more papers (counting any type of authorship) than native English speakers, in both the

317 COBRE-supported and control groups: 18.0-20.75 per investigator vs. 12.3-15.25 papers per

318 investigator.

319 Taking various metrics into account, predicting h-index into the future is only $0.48-0.67$

320 effective (Acuna, Allesina \& Kording, 2012), or 0.62-0.74 (for the single most predictive metric

$321=0.62$, and 37 features combined $=0.74)($ van Dijk, Manor \& Carey, 2014), while our single

322 metric of $1^{\text {st }}$-author papers within the preceding 10 years yields 0.95 predictive value of success.

323 Based on our formula, we would have predicted that only $2 / 20$ proposed junior faculty in

324 unfunded COBREs would ultimately succeed (3/20 actually did), while we would have predicted

325 that $12 / 20$ proposed junior faculty on funded COBREs would succeed (when 11/20 actually

326 succeeded) - scoring a 38/40 correct. Therefore, our study corroborates the evaluation and

327 funding decisions by NIH for our institution's COBRE grant submissions: only COBREs with the 328 more promising junior faculty were funded.

329 There are anecdotal reports that the potential of a trainee to become a successful

330 independent investigator can be judged early in the training experience (Creswell, 1986; Olds,

331 2001). However, to our knowledge, how and whether such a prediction can be substantiated by

332 quantifiable parameters (metrics) has not been explored, although metrics have recently been

333 employed to calculate chances of securing a job in academia (Acuna, Allesina \& Kording, 2012)

334 or to become a principal investigator based on authorship in databases (van Dijk, Manor \& Carey, 
335 2014). Interestingly, our analysis supports the notion that several $1^{\text {st }}$-author papers can make up

336 for lack of publications in top journals (van Dijk, Manor \& Carey, 2014).

337 Another interesting finding of our study is that having published in one high-impact

338 journal, even as first author, does not confer a significant increase in future success, and

339 publishing such papers as middle author does not increase success at all (as discussed above).

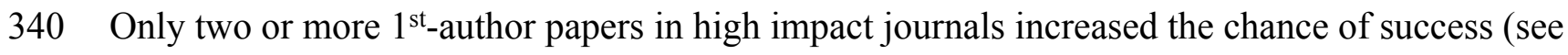

341 Fig. 2). This is contrary to common opinions and reports that tend to give candidates preference if

342 they have one publication in a top journal (Symonds, 2004; Acuna, Allesina \& Kording, 2012;

343 Schmid, 2013; van Dijk, Manor \& Carey, 2014). Our study indicates that the increased

344 intellectual involvement that $1^{\text {st }}$-authorship usually entails, provides the best guarantee of future

345 success if it can be sustained over several years, even if these papers are not published in high

346 impact journals. Accordingly, counting $1^{\text {st }}$-author papers may define a more dynamic pool of

347 junior faculty consisting of the ones with the intellectual drive, mentality and persistence to

348 become successful principal investigators (Creswell, 1986), while eliminating those who

349 contribute but overall have less intellectual involvement. This is in agreement with a recent large-

350 data study predicting principal investigator status (van Dijk, Manor \& Carey, 2014).

351 Limitations of our study are relatively small group sizes. We only assessed which metrics

352 predicted success in our environment (mid-sized university in a small state). We cannot

353 extrapolate our data for larger states, and elite universities. But our conclusions likely apply for

354 most medical schools - the " $99 \%$ " as opposed to the " $1 \%$ " institutions, and therefore should be

355 relevant for the large majority of academic medical centers. Future work will further probe the

356 validity of the 10 -year timeframe, refine the metrics during the transition from $1^{\text {st-author to last- }}$ 
357 author publishing, and examine the impact associated with temporary leaving academic research,

358 such as during maternity, teaching, or private sector employment.

359

360

361 Conclusions

362

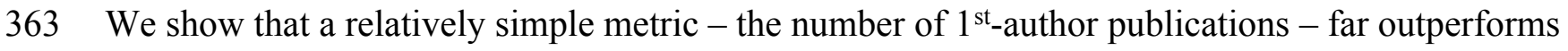

364 other metrics such as the h-index, journal impact factors, and citation rates in predicting research

365 success of junior faculty. However, proxies alone are insufficient in evaluating or predicting

366 faculty success, and further work is needed to determine which aspects of the COBRE and other

367 faculty development programs contribute to success. Nevertheless, our study can now be

368 replicated and validated at other biomedical institutions to predict the most suitable targets for

369 faculty development and to evaluate and improve various types of mentoring programs.

370

371

372 Acknowledgements

373

374 The authors thank Dr. Treg Gardner for computational support, Andrea Agarwal for data

375 management, and Drs. James Kenyon, Thomas Kozel, and David Westfall for helpful

376 discussions. 
378

379

380

381

382

383

384

385

386

387

388

389

390

391

392

393

394

395

396 Bornmann L, Mutz R, Hug SE, Daniel HD. 2011. A multilevel meta-analysis of studies reporting

\section{References}

Acuna DE, Allesina S, Kording KP. 2012. Future impact: Predicting scientific success. Nature 489:201-202.

Bakkalbasi N, Bauer K, Glover J, Wang L. 2006. Three options for citation tracking: Google Scholar, Scopus and Web of Science. Biomedical digital libraries 3:7.

Biswal AK. 2013. An absolute index (Ab-index) to measure a researcher's useful contributions and productivity. PLoS One 8: e84334

Bland CJ, Taylor AL, Shollen SL, Weber-Main AM, Mulcahy PA. 2009. Faculty success through mentoring: a guide for mentors, mentees, and leaders. Lanham, Md: Rowman \& Littlefield Publishing Group.

Bornmann L, Daniel HD. 2009. The state of $h$ index research. Is the $h$ index the ideal way to measure research performance? EMBO reports 10:2-6. 
397 correlations between the $\mathrm{h}$ index and 37 different $\mathrm{h}$ index variants. Journal of informetrics 5:346-

398359.

399

400 Bruce ML, Bartels SJ, Lyness JM, Sirey JA, Sheline YI, Smith G. 2011. Promoting the transition

401 to independent scientist: a national career development program. Academic medicine 86:1179-

4021184.

403

404 Buddeberg-Fischer B, Herta KD. 2006. Formal mentoring programmes for medical students and 405 doctors - a review of the Medline literature. Medical teacher 28:248-257.

407 Carpenter CR, Cone DC, Sarli CC. 2014. Using publication metrics to highlight academic

408 productivity and research impact. Academic emergency medicine 21:1160-1172.

409

410 Ceci SJ, Williams WM. 2011. Understanding current causes of women's underrepresentation in

411 science. Proceedings of the national academy of sciences USA 108:3157-3162.

412

413 Committee to evaluate the EPSCoR. The experimental program to stimulate competitive

414 research. The National Academies Press, Washington DC; 2013. Available at

415 http://www.nap.edu/openbook.php?record_id=18384\&page=R1 (accessed 5 February 2015)

416 
417 Creswell JW. 1986. Concluding thoughts: observing, promoting, evaluating, and reviewing

418 research performance. In: Creswell JW, ed. Measuring faculty research performance, New

419 directions for institutional research, vol. 50. San Francisco, Cal: Jossey-Bass Inc., 87-102.

420

421 Falagas ME, Pitsouni EI, Malietzis GA, Pappas G. 2008. Comparison of PubMed, Scopus, Web

422 of Science, and Google Scholar: strengths and weaknesses. FASEB journal 22:338-342.

423

424 Fried LP, Francomano CA, MacDonald SM, Wagner EM, Stokes EJ, Carbone KM, Bias WB,

425 Newman MM, Stobo JD. 1996. Career development for women in academic medicine: Multiple

426 interventions in a department of medicine. Journal of the American medical association

$427 \quad 276: 898-905$.

428

429 Hirsch JE. 2005. An index to quantify an individual's scientific research output. Proceedings of

430 the national academy of sciences USA 102:16569-16572.

431

432 Hirsch JE. 2007. Does the $\mathrm{h}$ index have predictive power? Proceedings of the national academy 433 of sciences USA 104:19193-19198.

435 Jacobi M. 1991. Mentoring and undergraduate academic success: a literature review. Review of 436 educational research 61:505-532. 
438 Kairouz VF, Raad D, Fudyma J, Curtis AB, Schünemann HJ, Akl EA. 2014. Assessment of

439 faculty productivity in academic departments of medicine in the United States: a national survey.

440 BMC medical education 14:205.

441

442 Khanna RK, Mouw JT. 1993. Prediction of academic success: A review of the literature and 443 some recommendations. College student journal 27:328-336.

445 Knapke JM, Tsevat J, Succop PA, Djawe K, Kuhnell P, Haynes EN. 2013. Publication track

446 records as a metric of clinical research training effectiveness. Clinical and translational science $447 \quad 6: 458-462$.

448

449 Knapke JM, Haynes EN, Kuhnell P, Tsevat J. 2015. NIH grant awards as a metric of clinical and 450 translational research training effectiveness. Clinical and translational science 8:52-56.

452 Laurance WF, Useche DC, Laurance SG, Bradshaw CJA. 2013. Predicting publication success 453 for biologists. BioScience 63:817-823.

454

455 McNutt M. 2014. The measure of research merit. Science 346:1155. 
457 Meagher E, Taylor L, Probsfield J, Fleming M. 2011. Evaluating research mentors working in the 458 area of clinical translational science: a review of the literature. Clinical and translational science $459 \quad 4: 353-358$.

460

461 Morzinski JA, Fisher JC. 1996. An evaluation of formal mentoring studies and a model for their 462 improvement. Evaluation practice 17:43-56.

463

464 Moss-Racusin CA, Dovidio JF, Brescoll VL, Graham MJ, Handelsman J. 2012. Science faculty's 465 subtle gender biases favor male students. Proceedings of the national academy of sciences USA 466 109:16474-16479.

468 Olds JL. 2001. Are there really too many biomedical trainees? Anatomical Record 265:157-158.

470 Page KR, Castillo-Page L, Wright SM. 2011. Faculty diversity programs in U.S. medical schools 471 and characteristics associated with higher faculty diversity. Academic medicine 86:1221-1228. 
473 Process Evaluation of the COBRE Program; 2008. Available at

474 http://www.nigms.nih.gov/Research/CRCB/IDeA/Documents/2008 evaluation_report.pdf

475 (accessed 9 June 2015)

476

477 Romanovsky AA. 2012. Revised h index for biomedical research. Cell cycle 11:4118-4121.

478

479 Sambunjak D, Straus SE, Marusić A. 2006. Mentoring in academic medicine: a systematic

480 review. Journal of the American medical association 296:1103-1115.

481

482 Schmid SL. 2013. Beyond CVs and Impact Factors: An Employer's Manifesto; 2013. Available 483 at

484 http://sciencecareers.sciencemag.org/career_magazine/previous_issues/articles/2013 09_03/care

485 dit.a1300186 (accessed 4 February 2015)

486

487 Schreiber M. 2008. A modification of the $\mathrm{h}$ index: The $\mathrm{h}_{\mathrm{m}}$-index accounts for multi-authored 488 manuscripts. Journal of informetrics 2:211-216.

490 Sheets KJ, Schwenk TL. 1990. Faculty development for family medicine educators: an agenda 491 for future activities. Teaching and learning in medicine 2:141-148. 
493 Steinert Y. 2000. Faculty development in the new millennium: key challenges and future

494 directions. Medical teacher 22:44-50.

495

496 Steinert Y. 2012. Perspectives on faculty development: aiming for $6 / 6$ by 2020. Perspectives on 497 medical education 1:31-42.

498

499 Steinert Y, McLeod PJ, Boillat M, Meterissian S, Elizov M, Macdonald ME. 2009. Faculty

500 development: a 'field of dreams'? Medical education 43:42-49.

501

502 Steinpreis RE, Anders KA, Ritzke D. 1999. The impact of gender on the review of the curricula

503 vitae of job applicants and tenure candidates: A national empirical study. Sex roles 41:509-528.

505 Symonds MRE. 2004. Nature and Science know best. Trends in ecology \& evolution 19:564.

507 Thorndyke LE, Gusic ME, George JH, Quillen DA, Milner RJ. 2006. Empowering junior

508 faculty: Penn State's faculty development and mentoring program. Academic medicine 81:668509673. 
511 Thorndyke LE, Gusic ME, Milner RJ. 2008. Functional mentoring: A practical approach with

512 multilevel outcomes. Journal of continuing education in the health professions 28:157-164.

513

514 van Dijk D, Manor O, Carey LB. 2014. Publication metrics and success on the academic job 515 market. Current biology 24:R516-517.

516

517 Wadhwa A, Das L, Ratnapalan S. 2014. Faculty development effectiveness: Insights from a

518 program evaluation. Journal of biomedical education, Article ID 286081, 5 pages.

519

520 Wingard DL, Garman KA, Reznik V. 2004. Facilitating faculty success: outcomes and cost

521 benefit of the UCSD National Center of Leadership in Academic Medicine. Academic medicine 522 79(10 Suppl):S9-11. 
Tables

526 Table 1. Characteristics of the two groups of junior faculty (Control=no COBRE; Experimental=with COBRE support) at the University of Nevada, Reno, 2000-2014.

\begin{tabular}{|c|c|c|c|c|c|c|c|c|c|c|}
\hline & $n$ & h-index & Ab-index & $\begin{array}{l}\text { \# of all } \\
\text { papers }\end{array}$ & $\begin{array}{l}\text { \# of } 1 \text { st } \\
\text { author } \\
\text { papers }\end{array}$ & $\begin{array}{l}\text { \# of } 1^{\text {st }} \text { author } \\
\text { papers } \\
\text { with high JIF }\end{array}$ & $\begin{array}{l}\text { \# of co-author } \\
\text { papers with } \\
\text { high JIF }\end{array}$ & $\begin{array}{l}\mathrm{M} / \mathrm{F} \\
\text { ratio }\end{array}$ & $\begin{array}{l}\text { Ethnicity: } \\
\text { Caucasian/ } \\
\text { Asian* }\end{array}$ & $\begin{array}{l}\text { English } \\
\text { as } 1^{\text {st }} \\
\text { language }\end{array}$ \\
\hline $\begin{array}{l}\text { Control: } \\
\text { no COBRE }\end{array}$ & 20 & $\begin{array}{l}10.65 \\
\pm 1.27\end{array}$ & $\begin{array}{l}177.6 \\
\pm 37.8\end{array}$ & $\begin{array}{l}14.9 \\
\pm 2.3\end{array}$ & $\begin{array}{l}4.45 \\
\pm 0.89\end{array}$ & $\begin{array}{l}0.90 \\
\pm 0.33\end{array}$ & $\begin{array}{l}2.35 \\
\pm 0.32\end{array}$ & $10 / 10$ & $18 / 2$ & $10 / 20$ \\
\hline $\begin{array}{l}\text { Mentored: } \\
\text { with COBRE }\end{array}$ & 20 & $\begin{array}{l}12.00 \pm \\
1.23\end{array}$ & $\begin{array}{l}148.6 \\
\pm 27.0\end{array}$ & $\begin{array}{l}17.5 \\
\pm 2.0\end{array}$ & $\begin{array}{l}6.85 \\
\pm 0.95\end{array}$ & $\begin{array}{l}0.80 \\
\pm 0.27\end{array}$ & $\begin{array}{l}1.35 \\
\pm 0.61\end{array}$ & $15 / 5$ & $14 / 6$ & $12 / 20$ \\
\hline $\begin{array}{l}\text { Statistics } \\
\text { (t-test) }\end{array}$ & & $p=0.449$ & $p=0.610$ & $p=0.394$ & $p=0.073$ & $p=0.816$ & $p=0.156$ & & & \\
\hline
\end{tabular}

Values \pm standard error of the mean (SEM); p-values are for unpaired t-test.

Abbreviations: COBRE, Center of Biomedical Research Excellence; JIF, Journal impact factor; M/F, male/female

* Only two ethnic categories were involved

Table 2. Comparison of junior faculty success rates and outcomes (Control=no COBRE; Mentored=with COBRE support) at the University of Nevada, Reno, 2000-2014.

551

\begin{tabular}{|c|c|c|c|c|c|c|c|c|}
\hline & $\begin{array}{l}\text { Overall } \\
\text { faculty } \\
\text { success }\end{array}$ & $\begin{array}{l}\text { Male } \\
\text { faculty } \\
\text { success }\end{array}$ & $\begin{array}{l}\text { Female } \\
\text { faculty } \\
\text { success }\end{array}$ & $\begin{array}{l}\text { English } \\
\text { as } 1^{\text {st }} \\
\text { language } \\
\text { success }\end{array}$ & $\begin{array}{l}\text { English as } \\
2^{\text {nd }} \text { or } 3^{\text {rd }} \\
\text { language } \\
\text { success }\end{array}$ & $\begin{array}{l}\text { Retention } \\
\text { at UNR }\end{array}$ & $\begin{array}{l}\text { Successful } \\
\text { faculty: } \\
\text { mean \# of } \\
1^{\text {st }} \text { author } \\
\text { papers }\end{array}$ & $\begin{array}{l}\text { Faculty } \\
\text { without success: } \\
\text { mean \# of } \\
\text { 1st author } \\
\text { papers }\end{array}$ \\
\hline No COBRE & $\begin{array}{l}15 \% \\
3 / 20\end{array}$ & $\begin{array}{l}30.0 \% \\
3 / 10\end{array}$ & $\begin{array}{l}0.0 \% \\
0 / 10\end{array}$ & $\begin{array}{l}10 \% \\
1 / 10\end{array}$ & $\begin{array}{l}20 \% \\
2 / 10\end{array}$ & $\begin{array}{l}40 \% \\
8 / 20\end{array}$ & $\begin{array}{l}11.33 \\
n=3 \\
p=0.19^{*}\end{array}$ & $\begin{array}{l}3.24 \\
\mathrm{n}=17\end{array}$ \\
\hline With COBRE & $\begin{array}{l}47.1 \% \\
8 / 17\end{array}$ & $\begin{array}{l}66.6 \% \\
10 / 15\end{array}$ & $\begin{array}{l}20.0 \% \\
1 / 5\end{array}$ & $\begin{array}{l}45.5 \% \\
5 / 11\end{array}$ & $\begin{array}{l}75 \% \\
6 / 8\end{array}$ & $\begin{array}{l}64.7 \% \\
11 / 17\end{array}$ & $\begin{array}{l}13.00 \\
n=11 \\
p=0.0002\end{array}$ & $\begin{array}{c}3.33 \\
n=9 \\
2^{* *}\end{array}$ \\
\hline Total $n$ & $37^{*}$ & $25^{*}$ & $15^{*}$ & 22 & 18 & $37^{*}$ & 14 & 26 \\
\hline $\begin{array}{l}\text { Statistics } \\
\text { (t-test) }\end{array}$ & $p=0.0404$ & & & & & $p<0.1$ & $p<0.00$ & 01 \\
\hline
\end{tabular}

${ }^{*} \mathrm{n}=37$ (not 40 ) for the overall success and retention calculation, because three successful faculty from the two current COBREs cannot yet be compared with their peers who are still being mentored.

** unpaired t-test; when all successful vs. non-successful faculty combined for \# of 1st-author papers, $p<0.0001$.

575 Abbreviations: COBRE, Center of Biomedical research Excellence; UNR, University of Nevada, Reno

576 


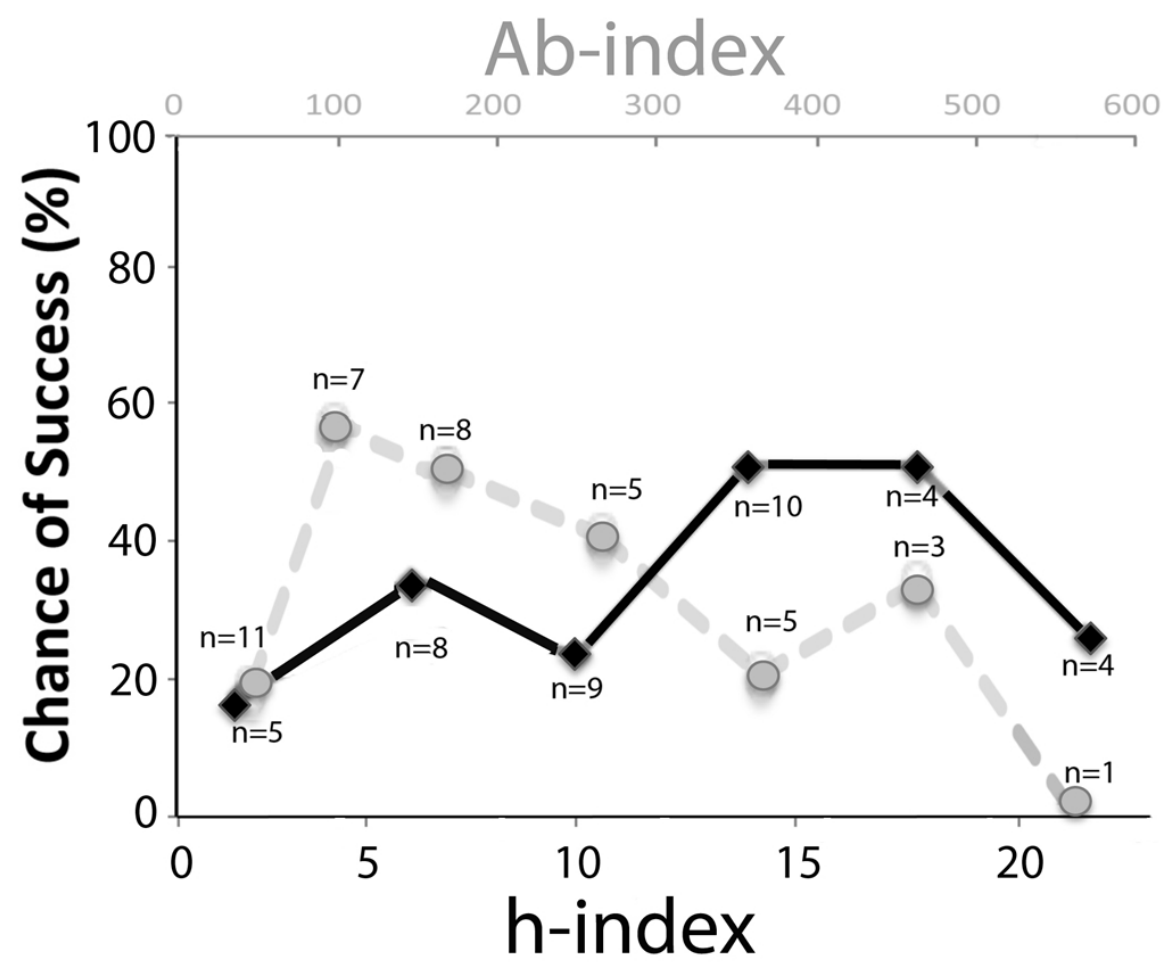

582

583 Fig. 1. The chances of success of junior faculty at the University of Nevada, Reno from 20002014 are plotted as a function of the h-index (Hirsch, 2005) (in increments of 3-5, black font,

585 lower x-axis) at the time of proposed start of COBRE mentoring. In addition, the chances of 586 success are plotted as a function of the Ab-index (Biswal, 2013) that takes co-authorship into 587 account (in increments of 50-100, grey, upper x-axis). The number of determinations for each 588 data point is indicated (n). Neither of these indices predicted success with more than $60 \%$, even 589 for selected subgroups, and dropped off at higher values. Total $n=40$, with $n=14$ successful and $590 \mathrm{n}=26$ not successful. 


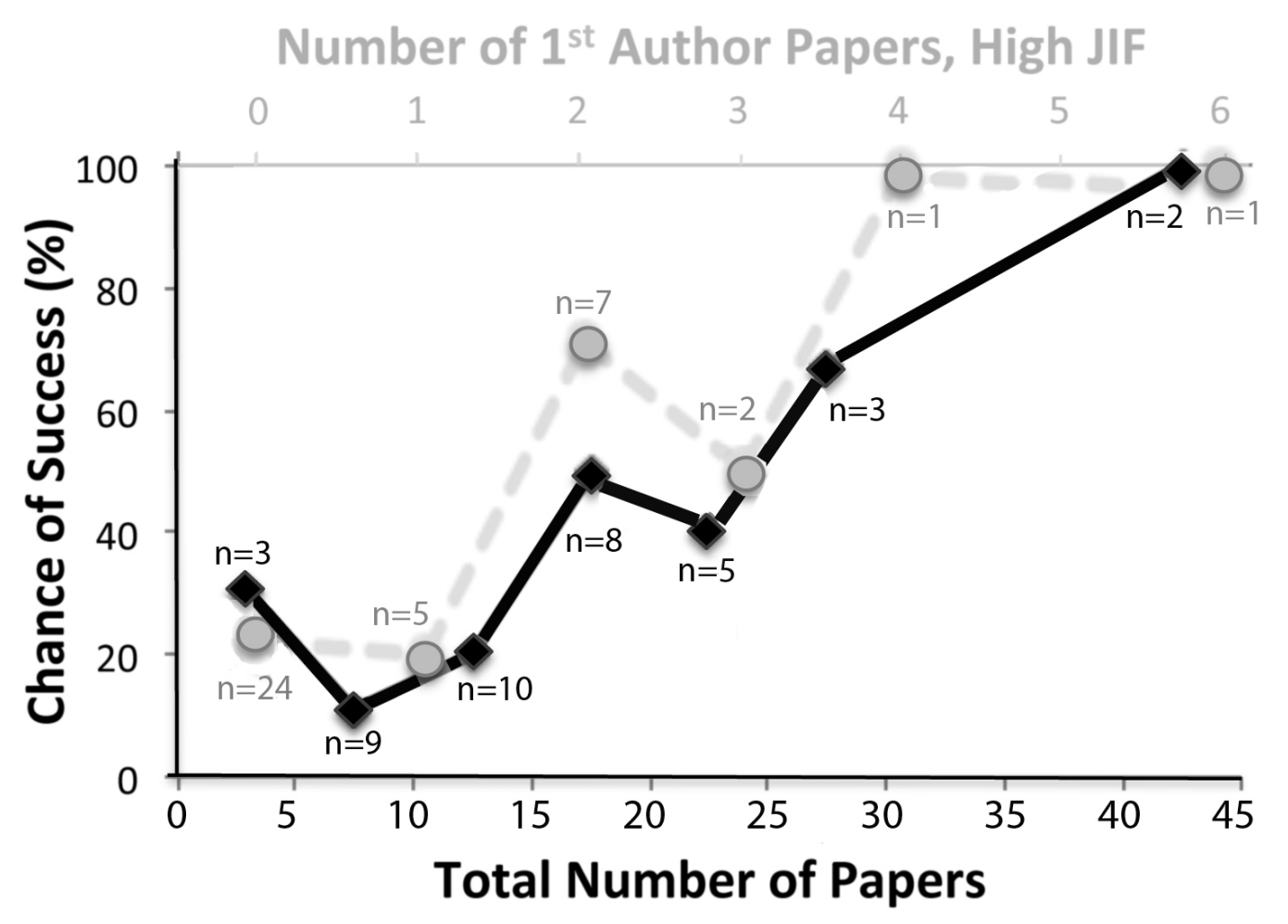

591

592 Fig. 2. The chances of success of junior faculty at the University of Nevada, Reno from 2000

5932014 are plotted as a function of the number of authored or co-authored papers in PubMed and

594 published prior to the time of proposed start of COBRE mentoring (in increments of 5, black font,

595 lower x-axis). In addition, the chances of success are plotted as a function of the number of $1^{\text {st }}$

596 author papers in journals with high impact factors (IF $>9$ ) (in increments of 1, grey, upper x-axis).

597 The number of determinations for each data point is indicated (n). Chances of success increased

598 with larger numbers, but they reached $100 \%$ only with the highest values, limiting a meaningful

599 prediction to a small percentage of faculty. Total $n=40$, with $n=14$ successful and $n=26$ not

600 successful. 


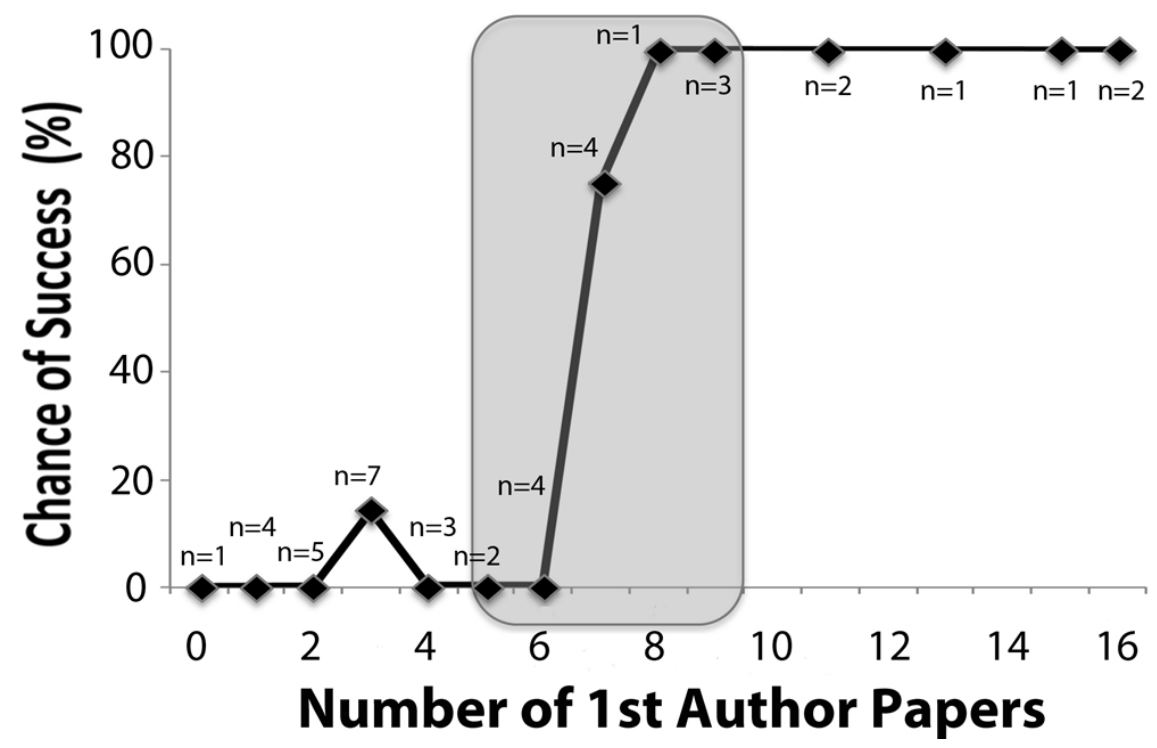

602

603 Fig. 3. The chances of success of junior faculty at the University of Nevada, Reno from 2000-

6042014 are plotted as a function of the number of $1^{\text {st }}$-author papers listed in PubMed and published

605 during the 10-year period prior to the date of the proposed start of COBRE mentoring (in

606 increments of $1, \mathrm{x}$-axis). The success rate flips from 1/24 (4.1\%) to 13/14 (92.9\%) between six

607 and seven $1^{\text {st }}$-authored papers in PubMed. Each data point represents between 1 and 7 faculty,

608 total $\mathrm{n}=40$. The number of $1^{\text {st }}$-authored papers in the preceding decade predicted outcome in

$60938 / 40(95 \%)$, and the difference of mean numbers of such papers per faculty, between successful

610 and not successful faculty, was significant with $\mathrm{p}<0.0001$ (

611 The shaded area from five-nine $1^{\text {st }}$-authored papers defines the pool of junior faculty to benefit

612 the most from a COBRE. 